RESEARCH ARTICLE

\title{
Non-rhizobial Root Nodule Endophytic Yeast, Candida tropicalis VYW1 Impacts Germination, Nodulation behavior and Metabolic flux in Blackgram (Vigna mungo L.)
}

\author{
Brundha Annadurai ${ }^{1}$, John kennedy $Z^{2}$ and Sivakumar Uthandi ${ }^{1}$ \\ ${ }^{1 *}$ Department of Agricultural Microbiology, Tamil Nadu Agricultural University, Coimbatore-641 003 \\ ${ }^{2}$ Post Harvest Technology, Tamil Nadu Agricultural University, Coimbatore-641 003
}

Received : $07^{\text {th }}$ May, 2020

Revised : $22^{\text {nd }}$ May, 2020

Accepted : $23^{\text {rd }}$ June, 2020

\begin{abstract}
Nodule associated endophytic yeasts have attracted much attention due to its potential plant growth-promoting activities and protecting legume crops from both biotic and abiotic stress. The present study evaluated the potential role of an endophytic yeast Candida tropicalis VYW1 in modulating host fitness (blackgram) both as a single inoculant and co-inoculant with Rhizobium sp. VRE1. The results showed that nodule associated endophytic yeast C. tropicalis VYW1 when co-inoculated with Rhizobium sp. VRE1 significantly increased the germination percent $(100 \%)$, root $(34.6 \mathrm{~cm})$, and shoot length $(32.8 \mathrm{~cm})$. The vigor index was also maximum (4250) in the treatment that received the co-inoculation of Rhizobium sp. VRE1 and $c$. tropicalis VYW1 besides registering enhanced hydrolytic enzyme, $\alpha$ - amylase, and protein content in seeds. Metabolite profiling of bacterial primed seed exudates revealed 30 diverse compounds belonging to the classes viz., sugars, amino acids, organic acids, flavones, prenol lipids, and fatty acids. The blackgram seeds primed with co - inoculants released hydroxyl benzoic acid and galactopyranose, which act as potential chemoattractants and involves in the lectin complement pathway regulating fructose mannose metabolism. These metabolites lead to a significant increase in germination and nodulation in blackgram seedlings. Hence, the study suggests the scope of enhancing the fitness of blackgram using a co-inoculant comprising of $C$. tropicalis VYW1 and Rhizobium sp. VRE1.
\end{abstract}

Keywords: Blackgram; Co-inoculant; Nodules; Non-Rhizobial endophytes; Rhizobium.

\section{INTRODUCTION}

Leguminous plants are symbiotically associated with rhizobia, involved in active nitrogen fixation, and this interaction plays a vital role in the production of legume crops. Blackgram (Vigna mungo. L) is an important pulse crop that occupies a unique place in Indian agriculture, where it has been grown since ancient times. Blackgram, also known as urdbean, is rich in protein (26\%) and contributes a large proportion of protein requirements to the Indian population. It is taken as split and also as whole grain and is crucial to supplement cerealbased diets. In India, blackgram is cultivated approximately 3.25 million ha with 1.45 million tonnes of annual production. It has been estimated that roughly $40-60$ million tonnes of atmospheric nitrogen are fixed annually by cultivated legume crops, which is essential not only for agriculture but also for the ecosystem functioning (Smil, 1999). Besides, nitrogen fixation could complement the use of synthetic nitrogen fertilizers that require ${ }^{*}$ Corresponding author's e-mail: usivakumartnau@gmail.com a considerable quantity of energy input during production and causes enormous environmental pollution. In legume - Rhizobium symbiosis, the rodshaped soil bacterium, Rhizobium, induces nitrogenfixing nodules on the roots of leguminous plants.

According to Tariq et al., (2012), ineffective rhizobial strains are also successful in legume rhizobia symbiosis due to two major reasons. i) Rhizobia are acquired by plants from the soil via an intricate signalling mechanism and are not transmitted directly from plant to offspring. ii) Plant is usually infected by multiple rhizobial strains leaving the chance for non-fixing strains inside the nodule. In order to prevent resource loss to ineffective rhizobial strains, plants adopt a strategy of partner choice and sanctions. To overcome limitations in legumerhizobia symbiosis, the interaction of rhizobia with other endophytic plant growth-promoting microbes (PGPM) holds a successful option that has to be explored. 
Co-inoculation of rhizobia with other plant growth-promoting rhizobacteria (PGPR) is one of the incredible resources to enhance nutrient availability and crop fitness for sustainable organic farming. PGPR are known to promote plant growth directly by the production of plant growth regulators, nutrient uptake, defense priming directly or indirectly by the production of metabolites like antibiotics, siderophore, and antagonistic against phytopathogens. Moreover, simultaneous infection with rhizobia and rhizobiome increases nodulation and growth in a wide variety of legumes (Rajendran et al., 2012). In the past, it was believed that nodule encounters only rhizobia, and now there is an introgression that unique signal attracts other microbial communities. The co-existence of other microbes inside the root nodules were termed as non-rhizobial root nodule endophytes (NRE). Some of the NRE including Agrobacterium, Arthrobacter, Bacillus, Paenibacillus, Enterobacter, Pseudomonas, Stenotrophomonas, Streptomyces, Micromonospora, Microbispora, and Candida sp. have been reported in different legumes (Velázquez et al., 2013; Le et al., 2016, Raja et al., 2019; Thanuja et al., 2020).

The presence of endophytic Chryseobacterium impacts the qualitative changes in the pattern of flavonoids exudation in the legumes (Ollero, 2010). The existence of countless interactions between NRE and Rhizobium sp. inside nodules benefiting each partners mediated by distinct chemical signalling contributes nodulation and nitrogen fixation (Schulz and Dickschat 2007). Furthermore, the mechanism by which NRE colonizes the root nodules or the conduit supports the nodulation process, or the plant growth promotion remains unknown. Whilst the NRE microbes were unveiled within the nodule niche, the functional role of this interaction is not yet unveiled. Nevertheless, there are several proposed hypothesis that NRE might enter infection threads along with Rhizobium (Zgadzaj et al., 2015), and type of soil, the exact interaction between the legumes and NRE is quite complicated. Though the plant growth-promoting activities of endophytic yeasts remain obscure, phyllosphere and rhizosphere yeasts from Drosera spatula with Indole acetic acid activity (IAA), 1-aminocyclopropane-1- carboxylic acid (ACC), siderophore, ammonia, and polyamine production has been reported (Aserse et al., 2013; Fu et al.,2016). This, plant growth-promoting traits of yeast strains are tolerant to saline stress (Rosenblueth and Martínez-Romero2006). Previously, we have isolated the NRE yeast, $C$. tropicalis VRE1 from root nodules of blackgram (Thanuja et al., 2017). The NRE Yeasts may also assist Rhizobium and other NRE counterparts by unique signalling compounds (Thanuja et al.,2020). This interaction may pose overall beneficial effects to legume - Rhizobium symbiosis compared to the presence of individual entity inside nodules.

With this perspective, the present study envisages the co-operative interaction of a nodule associated yeast strain Candida tropicalis VYW1 and Rhizobium sp. VRE1, both as a single culture and co-inoculant. The effect of this combination was elucidated during the early growth phase of blackgram in terms of germination, vigor index, nodulation efficiency, and metabolic changes.

\section{MATERIAL AND METHODS}

\section{Microbial strains and culture conditions}

C. tropicalis VYW1, and Rhizobium sp. VRE1 obtained from root nodules of Vigna mungo L., (Thanuja, et al., 2017; Thanuja et al., 2020) were grown in $100 \mathrm{~mL}$ of Tryptone yeast extract (TY) broth separately. The inoculated flasks were incubated at $28^{\circ} \mathrm{C}$ in a rotary shaker for 2-3 days until the logarithmic phase $\left(\sim 1 \times 10^{9}\right.$ viable cells $\left.\mathrm{mL}^{-1}\right)$ (Woomer et al., 2011). For co-inoculum preparation, a cocktail of the two strains was prepared in the ratio of $1: 1$, and the desired population $\left(10^{9} \mathrm{cfu} \mathrm{mL}^{-1}\right)$ was ensured prior to seed treatment.

\section{Seed biotization}

The rhizobial and non-rhizobial endophytic yeast isolates (C. tropicalis VYW1 and Rhizobium sp. VRE1) were bio-assayed for their effect on seedling growth using roll towel method described by Ju et al.,(2019). The seeds of Vigna mungo L., (var. VBN 6) were surface - sterilized by soaking in $3.5 \%$ sodium hypochlorite solution for $5 \mathrm{~min}$ and then washed thoroughly with sterile distilled water. The surface-sterilized healthy seeds were soaked with $2.0 \mathrm{~mL}$ of the log-phase culture of $C$. tropicalis VYW1 and Rhizobium sp. VRE1 for $1 \mathrm{~h}$. The seeds were biotized $(1 \mathrm{~h})$ with the prepared co-inoculum. In order to maintain the cell load, enumeration of the population on the seed surface was carried out in TY medium separately. The inoculated seeds were kept on sterilized germination paper and incubated at $30^{\circ} \mathrm{C}$. Seed germination percentage and seedling vigor was recorded on $8^{\text {th }}$ day of incubation. Seedling vigor was calculated on the seventh day using a formula as described below (Baki et al., 1973). Similarly, root and shoot lengths were recorded at different time intervals, such as 15, 30, and 45 days after sowing.

\section{Seed germination}

Seed germination percentage is the average number of seeds germinated over the period. In this study, germination percentage was calculated on the fifth day using the standard formulae:

Germination \% - Number of seeds germinated / Number of seeds placed $\times 100$ 


\section{Seed Vigour index}

Seed vigour index was examined after five days of incubation according to the formula based on the product of germination (\%) and seedling length (cm). Vigour Index = Germination (\%) $x$ Seedling Length $(\mathrm{Cm})$

\section{$\alpha$ - amylase activity and protein content}

The $\alpha$-amylase activity of Rhizobium sp. VRE1 and $C$. tropicalis VYW1 treated blackgram pregerminated seeds was determined (Muscolo et al., 2014). The protein content of germinated seeds was also determined (Ali Khan et al., 1972).

\section{Metabolic profiling of seed exudates using GC-MS}

\section{Extraction of seed exudates}

Exactly $50 \mathrm{~g}$ of healthy blackgram seeds (variety VBN 6) without any cracks and injuries were used for in vitro bio-assay studies. Surface sterilized blackgram seeds were divided into 12 portions, comprising three portions for each treatment. Each part consists of 20 seeds. Three parts of seeds were selected and soaked separately in Rhizobium sp. VRE1, C. tropicalis VYW1, and the respective co- inoculum cultures for $48 \mathrm{~h}$ in the dark. Cultures were prepared in saline or phosphate buffer, and the population maintained at $\sim 10^{9} \mathrm{cfu} . \mathrm{mL}^{-1}$. Final portions soaked in sterile water served as control. After $48 \mathrm{~h}$ of soaking, the seeds were removed from the suspension and placed for germination in Petri plates with pre-sterilized Whatman No1 filter paper. The sprouted seeds (5DAl) transferred aseptically into sterile water were kept in a shaker for $24 \mathrm{~h}$ to collect the exudates. The collected exudates were extracted by using equal volume of methanol as an extractant in a separating funnel. The set-up was kept under shaking condition (100 rpm) at $30^{\circ} \mathrm{C}$ overnight. The solvent layer was collected and allowed to air-dry under vacuum, and the air-dried residue was then dissolved in $1 \mathrm{~mL}$ of methanol. The concentrated seed exudates was filtered through $0.22 \mu \mathrm{m}$ pore filter membranes and checked for eventual contamination by plating an aliquot of $50 \mu \mathrm{l}$ in TY medium and incubated at $28^{\circ} \mathrm{C}$ for $24 \mathrm{~h}$ for microbial growth (Martins et al., 2018). The filtered extract was then injected into the sample port of GC-MS (Akila, 2019). The solvent fraction with the seeds metabolite compounds was combined and concentrated by evaporation in the rotary flask evaporator maintained at $60^{\circ} \mathrm{C}$ at 80 rpm. The concentrated crude metabolites obtained and dissolved in $1 \mathrm{~mL}$ HPLC grade methanol, filter sterilized and analyzed in GC/MS (Perkin Elmer ${ }^{\circledR}$, USA). The analysis conditions included: initial oven temperature at $35^{\circ} \mathrm{C}$ and increased to $140^{\circ} \mathrm{C}$ at a rate of $2^{\circ} \mathrm{C} \mathrm{min}-1$; the final temperature was $280^{\circ} \mathrm{C}$ that increased at the rate of $10^{\circ} \mathrm{C} \mathrm{min}-1$. The spectral bins obtained in GC/MS were analyzed, and the compounds were identified against the NIST mass spectral library (2014) based on most probable hits (Dheepa et al., 2016).

\section{Statistical analysis}

All data were statistically analyzed in Microsoft Excel and add-in with XLSTAT Version 2016.04.325250 (XLSTAT, 2010). Significant differences among the treatments were statistically analyzed using analysis of variance (ANOVA) and Duncan's Multiple Range Test (DMRT) at $p<0.05$ significance level.

\section{RESULTS AND DISCUSSION}

\section{NREY C. tropicalis VYW1 influenced the germination and nodulation behavior in blackgram}

Endophytes colonizing inside the plant tissues contribute to the fitness of the host, and in return, they gain nutrients and protection from the host (Rosenbleuth and Martinez Romero, 2006). In the present study, an investigation was conducted to evaluate the potential role of endophytic yeast C. tropicalis VYW1 in modulating the health of the blackgram both as an individual inoculant and coinoculant with Rhizobium sp.VRE1.

Table 1. Effect of biotization of blackgram seeds with co-inoculant of Rhizobium sp. and yeast strains

\begin{tabular}{lrrrrr}
\hline Treatment & Germination \% & Vigour Index & Nodules & Root length $(\mathbf{c m})$ & Shoot length (cm) \\
\hline Control & 82 & 1409 & 7 & $27.2 \pm 0.01^{\mathrm{d}}$ & $26.2 \pm 0.06^{\mathrm{d}}$ \\
Rhizobium sp. VRE1 & 94 & 2934 & 27 & $30.8 \pm 0.02^{\mathrm{c}}$ & $29.5 \pm 0.03^{\mathrm{c}}$ \\
C. tropicalis VYW1 & 94 & 3570 & 9 & $31.2 \pm 0.04^{\mathrm{b}}$ & $30.2 \pm 0.05^{\mathrm{b}}$ \\
Rhizobium sp. VRE1 + & 100 & 4250 & 32 & $34.6 \pm 0.01^{\mathrm{a}}$ & $32.8 \pm 0.04^{\mathrm{a}}$ \\
C. tropicalis VYW1 & & & & &
\end{tabular}

T1 - Absolute control without any treatments; T2 - Rhizobium sp. VRE1 alone; T3 - C. tropicalis VYW1 alone; T4 - Rhizobium sp. VRE1 + C. tropicalis VYW1; Values are mean ( \pm standard error) $(n=5)$, and values followed by the same letter in each column are not significantly different from each other on the observation day as determined by DMRT $(p \leq 0.05)$.

The growth parameters of blackgram such as germination percentage, root and shoot length, and the number of root nodules per plant were significantly increased by plant growth-promoting rhizobium and NREY C. tropicalis VYW1 and their combination when compared to control. However, 
the study revealed that the combined inoculation showed maximum seed germination (100\%), number of nodules (32 plant $^{-1}$ ), and vigor index (4250) followed by C. tropicalis VYW1 alone. More vividly, the individual culture of yeast treated seedlings augmented a drastic reduction in nodule counts as compared to the co-inoculant (Rhizobium $\mathrm{sp} .+$ C. tropicalis VYW1). While comparing with the individual inoculant of Rhizobium sp., the NREY C. tropicalis VYW1 performed significantly for the growth attributes viz., germination (94\%), and vigor index (3570) (Table 1). As perceived earlier, the individual inoculum with (Rhizobium sp.) showed the least performance than co-inoculated cultures (Rhizobium sp. VRE1 + C. tropicalis VYW1) in terms of germination percentage.

Table 2. NRE endophytic yeast and Rhizobium treated blackgram Seed exudates metabolites

\begin{tabular}{|c|c|c|c|c|c|c|c|}
\hline \multirow{2}{*}{$\begin{array}{l}\text { Seed exudates } \\
\text { metabolites }\end{array}$} & \multicolumn{4}{|c|}{ Treatments } & \multirow{2}{*}{ Chemical structure } & \multirow{2}{*}{ Functional role } & \multirow{2}{*}{ References } \\
\hline & $\mathrm{T} 1$ & $\mathrm{~T} 2$ & Т3 & T4 & & & \\
\hline$\beta$ - hydroxybenzoic acid & 0.109 & 1.29 & 0.987 & 2.318 & & $\begin{array}{l}\text { Chemo-attractants, influence the host } \\
\text { range of the interaction; Present in } \\
\text { soluble fraction of young nodules }\end{array}$ & Aguilar et al., 1988 \\
\hline Decane & 0 & 0.946 & 1.386 & 2.314 & & $\begin{array}{l}\text { Induce plant systemic resistance (ISR) } \\
\text { against pathogens }\end{array}$ & Lee et al., 2012 \\
\hline Phenol & 0 & 3.489 & 3.21 & 4.912 & & $\begin{array}{l}\text { Signal exchange between the legumes } \\
\text { and rhizobia during nodulation; } \\
\text { Contribute to transcriptional activities } \\
\text { of nod D dependent nod genes of } \\
\text { Rhizobium }\end{array}$ & $\begin{array}{l}\text { Mandal et al., } \\
2010\end{array}$ \\
\hline Cis - Vaccenic acid & 0 & 0.453 & 0 & 2.486 & & Plant growth regulation & Tariq et al., 2014 \\
\hline I-(+)-Ascorbic acid & 0 & 0.447 & 9.618 & 12.293 & & $\begin{array}{l}\text { Functions as an antioxidant, an enzyme } \\
\text { cofactor and as a precursor for oxalate } \\
\text { and tartrate synthesis }\end{array}$ & $\begin{array}{l}\text { Smirnoff and } \\
\text { Wheeler, } 2000\end{array}$ \\
\hline$\alpha-D$ - Glucopyranose & 0 & 0 & 0.879 & 2.521 & 아 & $\begin{array}{l}\text { Activates the lectin complement } \\
\text { pathway }\end{array}$ & $\begin{array}{l}\text { Hubbell, } 1975, \\
\text { Thanuja et al., } \\
2017,2020\end{array}$ \\
\hline
\end{tabular}

T1 - Un inoculated control; T2 - Rhizobium sp. VRE1; T3 - C. tropicalis VYW1; T4 - Rhizobium sp. VRE1 + C. tropicalis VYW1

The significant influence of NREY C. tropicalis VYW1 on germination of blackgram seeds might be attributed due to its plant-growth promoting traits and secondary metabolites (Thanuja et al., 2020; Brundha et al., 2020 Unpublished). Korir et al., (2017) found that co-inoculation of Bacillus strains with Bradyrhizobium japonicum in soybean plants provided the most significant increases in shoot and root length, nodule number and total biomass, total nitrogen and grain yield (Bai et al., 2003). Similar to our findings, previous works also confirmed that the benefits bestowed by co-inoculation on plant health, especially in legumes on nodule development, are consistent (Walpola and Yoon, 2013; Morel et al., 2012; Korir et al., 2017). Further, the yeast strain, C. tropicalis VYW1 showed indirect PGP characters such as polyamine production and high ACC deaminase activity, siderophore, polyamines, and ammonia production (Thanuja et al., 2020). Besides, PGP yeasts exhibit antagonistic action against plant pathogens (Ferraz et al., 2019). Thus the present investigation suggests that the co-operative interaction between rhizobia and non- rhizobial endophytic yeast (NREY) is of relevance in the enhancement of nodulation efficiency, vigor index, shoot, and root length and total biomass in blackgram.

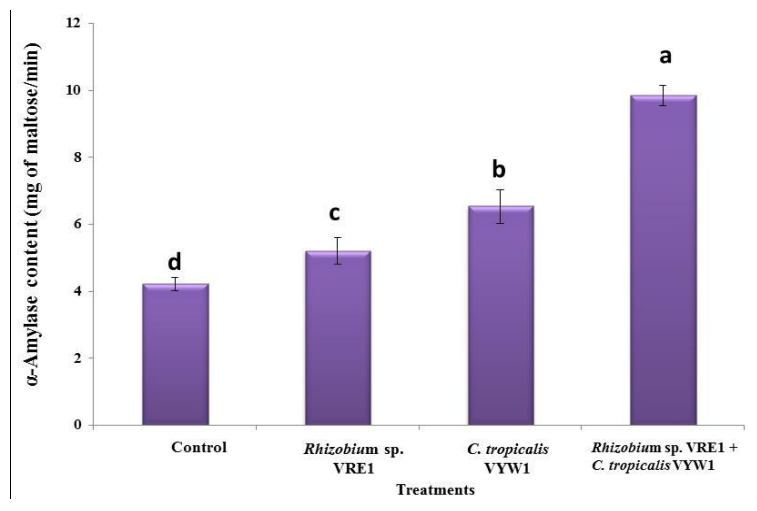

Figure 1. $\alpha$ - Amylase content of germinating blackgram seeds treated with Rhizobium sp. and NRE yeast strain. Bars with the same letter are not significantly different from each other on the observation, as determined by DMRT ( $\leq \leq 0.05$ ). 


\section{NREY C. tropicalis VYW1 triggered hydrolytic enzymes during seed germination}

Amylases are the important hydrolytic enzymes that increase sugars in germination seeds of rice (Kaur et al., 2005). Starch is hydrolyzed by the amylolytic enzymes to provide substrate and energy sources for the embryo during germination, and derived monosaccharide sugars provide energy for the shoot and root development. Furthermore, while working with wheat seeds, Das and mandi (1992) observed a considerable increase in $\alpha$-amylase activity during imbibition and the onset of the germination process.

Accordingly, in the present investigation, the $\alpha$ amylase content ( $\mathrm{mg}$ of maltose $\mathrm{min}^{-1}$ ) of the blackgram seeds biotized with $C$. tropicalis VYW1 and Rhizobium sp. VRE1 was found to be significantly increased. However, increased $\alpha$-amylase activity (9.78 $\mathrm{mg}$ of maltose $\mathrm{min}^{-1}$ ) was observed in seeds treated with co-inoculum, followed by $C$. tropicalis VYW1 (6.24 mg of maltose $\mathrm{min}^{-1}$ ), and the Rhizobium sp. VRE1 treated blackgram germinated seeds recorded the lowest value of (5.44 $\mathrm{mg}$ of maltose $\min ^{-1}$ ) (Figure1).

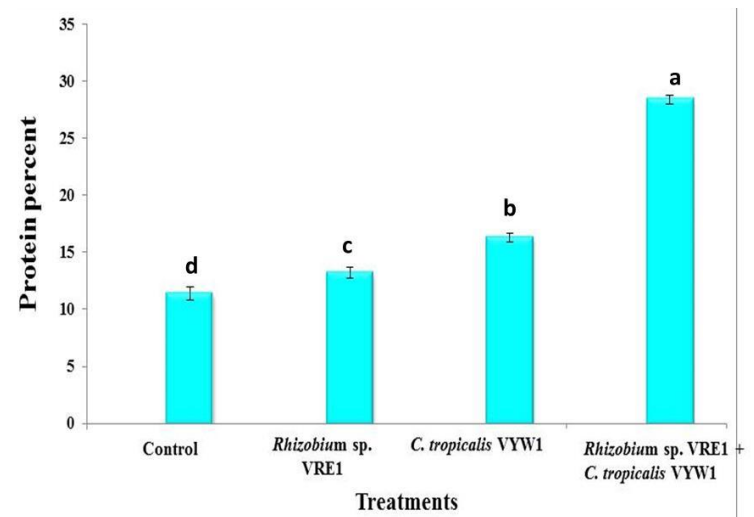

Figure 2. Protein percent of germinating blackgram seeds treated with Rhizobium sp. and NRE yeast strain. Bars with the same letter are not significantly different from each other on the observation, as determined by DMRT ( $p \leq 0.05$ ).

The simultaneous increase in soluble sugars and amylase activity and decrease in starch could be due to a faster breakdown of starch. The results also suggest that $C$. tropicalis VYW1 triggered the germination process via hydrolytic enzyme activities.

During seed germination, starch hydrolysis is mediated by the enzyme $\alpha$-amylase, which produces soluble oligosaccharides essential for other metabolic functions (Kaur et al., 2005). Accordingly, the enhanced $\alpha$-amylase activity due to bacterial priming suggests better bioconversion of starch into other oligo-sugars.

\section{C. tropicalis VYW1 remobilizes seed reserves during seed germination}

Storage proteins are mobilized to provide nutrients for seedling growth during seed germination (Wang et al., 2017). The present investigation witnessed the highest average protein content (28.4\%) in blackgram seeds biotized with combined inoculum (C. tropicalis VYW1 and Rhizobium sp. VRE1), followed by single inoculant of $C$. tropicalis VYW1 (16.3\%) and Rhizobium (13.2\%) (Figure2). Similar to growth attributes, here also, the interaction between rhizobium and non- rhizobial endophytic yeast acted synergistically and altered the metabolic flux. However, none of the research has shown non-rhizobial endophytic yeast as a component of co-inoculum to date. This research opened an insight on growth-promoting endophytic yeasts of the nodule and its prospect as a novel bio-inoculant for enhancing pulse productivity.

Metabolite profiling of co-inoculant primed seed exudates revealed chemo-attractants and antioxidants

Diverse class of metabolites (approximately 25 classes) was observed in the seeds treated with C. tropicalis VYW1 and Rhizobium sp.VRE1, as well as their respective co-inoculant (Figure 3 ). The seed exudates contained sugars such as glucose and xylose. However, the exudates from the untreated blackgram seeds composed of derivatives of benzoic acid, succinic acid, coumarin, ascorbic acid, and carotenoids (Table 2). Fatty acyls, carboxylic acid derivatives, benzene and substituted derivatives, phenylpropanoids, prenol lipids, and steroids are predominant in the seeds treated with co-inoculant as compared to the respective mono-culture.

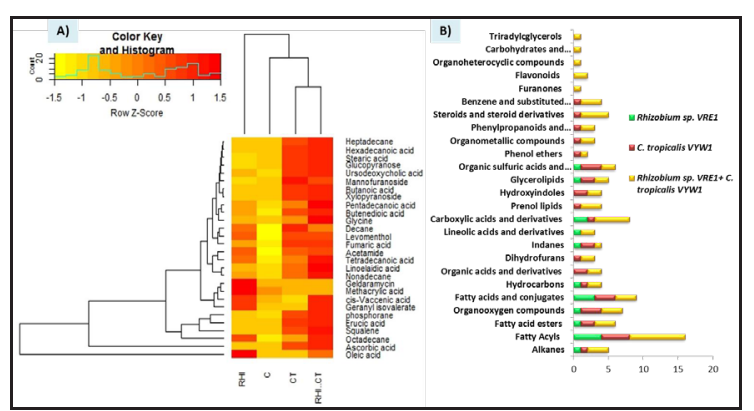

Figure 3. A) Distribution pattern of metabolites in seed exudates mediated by blackgram endophytes; B) Metabolites detected in seed exudates of biotized blackgram seeds (VBN 6) based on their differences in relative abundance; C- Control; RHI - Rhizobium sp. VRE 1; CT - C. tropicalis VYW 1; RHI+CT - Rhizobium sp. VRE 1 + C. tropicalis VYW 1.

The Z score value $>1.0$ and deep intensity of red color in the heat map affirms the increase in the area percent of compounds such as ascorbic 
acid, squalene, glucopyranose, mannofuranoside, hexadecanoic acids and other fatty acid derivatives in co-inoculant and C. tropicalis VYW1 treated seeds. The functional role of critical metabolites is elucidated in Table 2. Further, the results suggest that the exudates of NREY, as well as co-inoculant treated seeds, showed more chemo-attractants, which aids in more colonization of the inoculant on the seed surface (Aguilar et al., 1988). The antioxidants would have prevented dehydration of seeds, and the sugars played a crucial role in mitigating the $\mathrm{C}$ requirement of the augmented bio-inoculant (Smirnoff and Wheeler, 2000). The metabolite candidates serving for $\mathrm{C}$ assimilation provided the energy demand of the co-inoculant (C. tropicalis VYW1 and Rhizobium sp.VRE1), which might be a successful means for their survival. The signalling factors of $C$. tropicalis VYW1 that elicited the secretion of such sugar derivatives and fatty acyls need to be explored. In general, the seed exudates are comprised of a mixture of sugars and acids. Crop seeds exudates contain sugars such as glucose, fructose, and maltose, which act as a source of nutrients for the rhizosphere microflora. Along with those sugars and acids, certain other compounds such as volatiles that could alter the metabolism of plant microbiome may be present. Identification of these compounds would lead to the discovery of newer pathways by which the host plants are benefited from their endophytic microbiota (Lugtenberg et al., 1999).

\section{CONCLUSION}

The present study clearly demonstrated the cooperative interaction of non- rhizobial endophytic yeast strain C. tropicalis VYW1 and Rhizobium sp. VRE1. Co-inoculation of promising non- rhizobial endophytic yeast with the symbiotic Rhizobium increased the germination attributes, vigour index, nodulation behavior, and metabolic flux of blackgram seedlings. Hence, the results paved a way to develop a potential yeast-based co-inoculum for sustainable pulse productivity.

\section{ACKNOWLEDGEMENT}

This study was supported by the Ministry of Human Resource Development, Government of India through MHRD-FAST-CoE (F.No.5-6/2013-TSVII) sanctioned to SU.

\section{REFERENCES}

Aguilar, J.M.M., Ashby, A.M., Richards, A.J.M., Loake, G. J., Watson, M.D and C.H. Shaw.1988. Chemotaxis of Rhizobium leguminosarum biovar. phaseolitowards flavonoid inducers of the symbiotic nodulation genes. J. Genet Microbiol. 134: 2741-2746.

Akila, P. and M. Senthilkumar. 2019. Methylorubrum induced moisture stress tolerance and phyto hormone regulation in tomato, (Thesis).
Ali Khan S. T. and C.G. Youngs. 1973. Variation in protein content of field peas. Can J Plant sci. 53: 37-41.

Aserse, A.A., Räsänen, L. A., Aseffa, F., Hailemariam, A. and K. Lindström. 2013. Diversity of sporadic symbionts and non-symbiotic endophytic bacteria isolated from nodules of woody, shrub, and food legumes in Ethiopia. Appl Microbiol Biotechnol. 97(23): 10117-10134.

Brundha., A., Sugitha, T., John Kennedy, Z. and Sivakumar U. 2020. Endophytic Yeast Occupy the Nodule Niche Orchestrating nod Factors and Nodulation by Rhizobium sp. in Blackgram (Vigna mungo L.) (Submitted in Scientific reports - under review process).

Dardanelli, M. S., Manyani, H., González B.S., RodríguezCarvajal, M.A., Gil-Serrano, A.M., Espuny, M.R., López-Baena, F.J., Bellogin, R.A., Megias, M. and F. J. Ollero. 2010. Effect of the presence of the plant growth promoting rhizobacterium (PGPR) Chryseobacterium balustinum Aur9 and salt stress in the pattern of flavonoids exuded by soybean roots. Plant soil. 328(1-2): 483-493.

Dheepa, R., Vinodkumar, S., Renukadevi, P. and S. Nakkeeran. 2016. Phenotypic and molecular characterization of chrysanthemum white rust pathogen Puccinia horiana (Henn) and the effect of liquid based formulation of Bacillus spp. for the management of chrysanthemum white rust under protected cultivation. Biol control. 103: 172-186.

Ferraz, P., Cássio, F. and C. Lucas. 2019. Potential of Yeasts as Bio-control Agents of the Phytopathogen Causing Cacao Witches' Broom Disease: Is Microbial Warfare a Solution? Front Microbiol. 10: 1766.

Fu, S.F., Sun, P.F., Lu, H.Y., Wei, J.Y., Xiao, H.S., Fang, W.T., Cheng, B.Y. and J.Y. Chou. 2016. Plant growth-promoting traits of yeasts isolated from the phyllosphere and rhizosphere of Drosera spatulata Lab. Fungal boil. 120(3): 433-448.

Geetha Thanuja, K.G., Brundha, A., Sugitha, T and Sivakumar U. 2020. Non-rhizobial Endophytic (NRE) Yeasts Assist Nodulation of Rhizobium in Root Nodules of Blackgram (Vigna mungo L.). Arch Microbiol. (Revision submitted (AOMI-D -2000283R1).

GeethaThanuja, K.G, Brundha, A., Sugitha, T.C.K. and S. Uthandi. 2017. Non - Rhizobial endophytic yeast C. tropicalis VYW1 associated with root ndules of blackgram - endowed with plant growth promoting attributes (Association of Microbiologists of India (AMI) conference).

Hubbell, F.B. 1975. Cross-reactive antigens and lectin as determinants of symbiotic specificity in the Rhizobium-clover association.J Appl Microbiol. 30: 1017-1033.

Ju, W., Liu, L., Fang, L., Cui, Y., Duan, C. and H. Wu. 2019. Impact of co-inoculation with plant growth promoting rhizobacteria and Rhizobium on the biochemical responses of alfalfa - soil system in copper contaminated soil. Ecotoxicol Environ Saf. 167: 218-226.

$107|4-6| 180$ 
Kaur, R., Liu, X., Gjoerup, O., Zhang, A., Yuan, X., Balk, S. P., Schneider, M. C. and M. L. Lu. 2005. Activation of p21 - activated kinase 6 by MAP kinase kinase 6 and p38 MAP kinase. J Biol Chem. 280(5): 3323-3330.

Korir, H., Mungai, N. W., Thuita, M., Hamba, Y. and C. Masso. 2017. Co-inoculation effect of rhizobia and plant growth promoting rhizobacteria on common bean growth in a low phosphorus soil. Front plant sci. 8: 141.

Le, X.H., Franco, C.M., Ballard, R. A. and E. A. Drew. 2016. Isolation and characterisation of endophytic actinobacteria and their effect on the early growth and nodulation of lucerne (Medicago sativa L.). Plant Soil. 405(1-2): 13-24.

Lee, B., M. A. Farag, H.B. Park, J.W. Kloepper S. H. Lee and C.M. Ryu .2012. Induced resistance by a long-chain bacterial volatile: elicitation of plant systemic defense by a $\mathrm{C} 13$ volatile produced by Paenibacillus polymyxa. PLoS ONE. 7: 487 - 494.

Lugtenberg, B. J., Kravchenko, L.V. and M. Simons.1999. Tomato seed and root exudate sugars: composition, utilization by Pseudomonas bio control strains and role in rhizosphere colonization. Environ Microbiol. 1(5): 439-446.

Mandal, S.M., M. Mandal A.K. Das B.R. Pati and A.K Ghosh. 2009. Stimulation of indoleacetic acid production in a Rhizobium isolate of Vignamungoby root nodule phenolic acids. Arch Microbiol. 191: 389-397.

Martins S.J., Flávio, H.V. Medeiros, H.V. and V. Lakshmanan and Harsh P. Bais. 2018. Impact of Seed exudates on growth and biofilm formation of Bacillus amyloliquefaciens ALB629 in Common Bean. World J Microbiol Biotechnol. 22: 983-990.

Morel,M. A., Braña, V. and S. C. Sowinski. 2012. Legume crops, importance and use of bacterial inoculation to increase production. Crop plant. 12: 218-240.

Muscolo, A., Sidari, M., Anastasi, U., Santonoceto, C. and A. Maggio. 2014. Effect of PEG - induced drought stress on seed germination of four lentil genotypes. J Plant Interact. 9(1): 354-363.

Ollero, M.S.D. 2010. Effect of the presence of the plant growth promoting rhizobacterium (PGPR) Chryseobacterium balustinum Aur9 and salt stress in the pattern of flavonoids exuded by soybean roots. Plant and Soil. 328: 483-493.

Paul A, Mukh Erji K.S and S. M. Sircar 1970. Metabolic changes in rice seeds during storage. Ind J Agric Sci. 40(12): 1031-1036.

Raja, S. R. T., Sugitha, T. and S. Uthandi. 2019. NonRhizobial Nodule Associated Bacteria (NAB) From Blackgram (Vigna mungo L.) and their possible role in plant growth promotion. Mad Agrl J. 106: $143-151$.

Rajendran, G., Patel, M.H. and S.J. Joshi. 2012. Isolation and characterization of nodule-associated Exiguobacterium $\mathrm{sp}$. from the root nodules of fenugreek (Trigonellafoenum graecum) and their possible role in plant growth promotion. Int J Microbiol. 132-143.
Rosenblueth, M. and E. Martínez-Romero. 2006. Bacterial endophytes and their interactions with hosts. Mol Plant Microbe Interact. 19(8): 827-837.

Schulz, S. and J. S. Dickschat. 2007. Bacterial volatiles: the smell of small organisms. Nat Prod Rep. 24(4): 814-842.

Smil, V. 1991. Population growth and nitrogen: an exploration of a critical existential link. Population and Development Review. 569-601.

Smirnoff, N. and G.L. Wheeler. 2000. Ascorbic acid in plants: biosynthesis and function. Crit. Rev. Plant Sci. 19(4): 267-290.

Tariq, M., Hameed, S., Yasmeen, T. and A. Ali. 2012. Non-rhizobial bacteria for improved nodulation and grain yield of mung bean [Vigna radiata (L.) Wilczek]. Afr. J.Biotechnol. 11(84): 15012-15019.

Tariq, S. Hameed, T. Yasmeen, M. Zahid and M. Zafar. 2014. "Molecular characterization and identification of plant growth promoting endophytic bacteria isolated from the root nodules of pea (Pisum sativum L.). World J. Microbiol Biotechnol. 30(2): $719-725$.

Thanuja, K.G., Brundha, A., Sugitha, T.C.K. and U. Sivakumar. 2017. Non - Rhizobial endophytic yeast C. tropicalis VYW1 associated with root ndules of blackgram - endowed with plant growth promoting attributes (AMI conference).

Thanuja, K.G., Brundha, A., Sugitha, T.C.K. and U. Sivakumar. 2020. Non-rhizobial endophytic (NRE) yeasts assist nodulation of Rhizobium in root nodules of blackgram (Vigna mungo L.). Arch Microbiol. DOI 10.1007/s00203-020-01983-z.

Velázquez, E., Martínez-Hidalgo, P., Carro, L., Alonso, P., Peix, A., Trujillo, M.E. and E. MartínezMolina. 2013. Nodular endophytes: an untapped diversity. Bene Plant - Micro Interact: Ecol and Appl. 215-235.

Walpola, B.C. and M.H. Yoon. 2013. Isolation and characterization of phosphate solubilizing bacteria and their co-inoculation efficiency on tomato plant growth and phosphorous uptake. Afr J Microbiol Res, 7(3): 266-275.

Wang, C., Knill, E., Glick, B. R. and G. Défago. 2000. Effect of transferring 1- aminocyclopropane - 1 -carboxylic acid (ACC) deaminase genes into Pseudomonas fluorescens strain $\mathrm{CHAO}$ and its gacA derivative $\mathrm{CHA96}$ on their growth- promoting and disease - suppressive capacities. Can $J$ Microbiol. 46 (10): 898-907.

Woomer, P. L., Karanja, N., Kisamuli, S. M., Murwira, M. and A. Bala. 2011. A revised manual for rhizobium methods and standard protocols available retrieved from: www.N2Africa.org.

XLSTAT.2010. XLSTAT. Add in soft SARL, Paris. http:// www.xlstat.com

Zgadzaj, R., James, E. K., Kelly, S., Kawaharada, Y., De Jonge, N., Jensen, D.B., Madsen, L. H. and S. Radutoiu.2015.A legume genetic framework controls infection of nodules by symbiotic and endophytic bacteria. PLoS Genet. 11(6): 52-80. 